\title{
Hypoxic hepatitis with marked elevation of serum ferritin probably due to acti- vation of intrahepatic macrophages: another form of hypoxic hepatitis hitherto not reported?
}

\author{
M. Tanaka',2, T. Goya', H. Suzuki', M. Takahashi', K. Imoto', M. Kurokawa', S. Tashiro', A. Kuwano', S. Okada², M. \\ Kato $^{1}$, M. Kohjima ${ }^{1}$, K. Kotoh ${ }^{3}$, Y. Ogawa \\ (1) Department of Medicine and Bioregulatory Science, Graduate School of Medical Sciences, Kyushu University, 3-1-1 Maidashi, Higashi-ku, Fukuoka 812-8582, Japan ; \\ (2) Division of Pathophysiology, Department of Immunology and Neuroscience, Medical Institute of Bioregulation, Kyushu University, 3-1-1 Maidashi, Higashi-ku, \\ Fukuoka 812-8582, Japan ; (3) Division of Hepatology, Harasanshin Hospital, 1-8 Taihakumachi, Hakata-ku, Fukuoka 812-0033, Japan.
}

\begin{abstract}
Background and study aims : Hypoxic hepatitis (HH) is an acute liver injury that develops in patients with underlying diseases, such as heart failure, respiratory failure, septic/toxic shock. However, some patients do not have underlying diseases or episodes which are known to result in HH. Here, we analyzed the clinical characteristics of this particular patient group (called 'unknown HH' hereafter) to understand its pathogenesis.

Patients and methods : Between October 2010 and January 2016, 157 consecutive patients with acute liver injury were admitted to our hospital. Among these patients, 15 patients were categorized as unknown HH. Medical histories and blood test results of unknown HH were analyzed.

Results : Among 15 patients of unknown HH, 11 were habitual drinkers and all experienced one of digestive symptoms which might result in mild hypovolemia such as vomiting, diarrhea, appetite loss, and epigastralgia. All patients of unknown HH presented marked elevation of serum ferritin concentration paralleled with aspartate transaminase (AST), alanine transaminase (ALT), and lactate dehydrogenase (LDH) concentrations. The serum levels of ferritin, ALT, LDH, and prothrombin time-international normalized ratio (PT-INR) were rapidly decreased during hospitalization and all 15 patients of unknown $\mathrm{HH}$ recovered without any complication.

Conclusions: We found the particular group of $\mathrm{HH}$ with marked elevation of serum ferritin probably due to intrahepatic macrophage activation. Anti-inflammatory treatments might be effective for this group of hypoxic hepatitis. (Acta gastroenterol. belg., 2021, 84, 317-320).
\end{abstract}

Key words : acute liver injury, hepatic microcirculation, fibrin deposition, autophagy.

Abbreviations: HH (hypoxic hepatitis), AST (aspartate transaminase), ALT (alanine transaminase), LDH (lactate dehydrogenase), PT-INR (prothrombin time-international normalized ratio), HAV (hepatitis A virus), HBV (hepatitis $\mathrm{B}$ virus), $\mathrm{HCV}$ (hepatitis $\mathrm{C}$ virus), $\gamma$-GTP ( $\gamma$-glutamyl transpeptidase), FDP (fibrin degradation product), TASIT (transcatheter arterial steroid injection therapy), AN (anorexia nervosa).

\section{Introduction}

Hypoxic hepatitis $(\mathrm{HH})$ is a type of acute liver injury that occurs mostly in patients with cardiac, respiratory, or circulatory failure $(1,2)$. $\mathrm{HH}$ is defined by three conditions, a clinical setting prone to reduced oxygen delivery or utilization by the liver, a drastic and transient increase in serum aminotransferase level, and exclusion of other causes of liver injury such as viral hepatitis or drug-induced liver injury (2). The prognosis of patients with $\mathrm{HH}$ is generally poor, with reported in-hospital mortality rates of $45-72 \%$ (3-6).

Ninety percent of the underlying diseases of $\mathrm{HH}$ is due to reduced cardiac output, respiratory failure, or septic/ toxic shock (3-6). HH can be caused by hypoglycemia in children, liver cirrhosis, diffuse metastatic infiltration into the liver, heatstroke, sickle cell disease, grand mal seizure, extreme anemia, obstructive sleep apnea, aortic aneurysm, acute lower limb ischemia, Budd-Chiari syndrome, and hereditary hemorrhagic telangiectasia (1). However, some patients do not have underlying diseases or episodes which are known to result in $\mathrm{HH}$.

Here, we analyzed the clinical characteristics of this particular patient group (called 'unknown HH') to understand the mechanism of hypoxic hepatitis in this group.

\section{Methods}

Between October 2010 and January 2016, 157 consecutive patients with acute liver injury were admitted to our hospital. Seven patients in the late stage of acute liver failure on admission were excluded. Causes of acute liver injury in the remaining 150 patients were hepatitis A virus (HAV) infection (18 patients), hepatitis $\mathrm{B}$ virus (HBV) infection (26 patients), hepatitis $\mathrm{C}$ virus (HCV) infection (one patient), autoimmune hepatitis (26 patients), Epstein-Barr virus infection (three patients), drugs (12 patients), alcohol (15 patients), Wilson's disease (four patients), adult-onset Still disease (two patients), hepatic amyloidosis (one patient), HH (20 patients) and undetermined etiology (22 patients). Among 20 patients of $\mathrm{HH}, 5$ patients had underlying diseases including chronic heart failure or causative episodes such as shock

\footnotetext{
Correspondence to : Motoyuki Kohjima, 3-1-1 Maidashi, Higashi-ku, Fukuoka 812-8582, Japan. Phone : (+81) 92-642-5282. Fax : (+81) 92-642-5287. Email : kohjima@med.kyushu-u.ac.jp

Submission date : $22 / 06 / 2020$

Acceptance date : 09/10/2020
} 
state and sepsis. We defined fifteen patients who did not have underlying diseases or episodes which are known to result in $\mathrm{HH}$ as 'unknown $\mathrm{HH}$ ' group.

Medical histories and blood test results on admission were recorded; the latter included complete blood cell counts, general hepatic function tests, coagulation ability including disseminated intravascular coagulation markers, and viral markers. Temporal changes during hospitalization in general hepatic function tests and coagulation ability, as well as treatment methods and prognosis in the $\mathrm{HH}$ patients were also recorded.

This study was approved by the Kyushu University Hospital Ethics Committee. Informed consent of individual patients was not obtained because this study was designed as a retrospective study.

\section{Results}

Clinical characteristics on admission of the unknown $\mathrm{HH}$ group

The mean age of unknown HH was 40 years old (1881 ) and 11 of them were male and four were females (Table 1). Before admission, five patients of unknown HH were heavy drinkers (daily alcohol intake $>120 \mathrm{~g}$ ), six were regular drinkers ( $>60 \mathrm{~g})$, and four were non-drinker (Table 1). Their blood test results could be distinguished from those of alcoholic hepatitis which is generally characterized by markedly elevated bilirubin levels, moderately elevated transaminases usually below 300 $\mathrm{IU} / \mathrm{mL}$ with an AST/ALT ratio $>2$, elevated $\gamma$-glutamyl transpeptidase $(\gamma-\mathrm{GTP})$, and leukocytosis with neutrophil predominance (7).

Just before the onset of liver injury, seven patients of unknown $\mathrm{HH}$ experienced vomiting, two had diarrhea, seven had appetite loss or epigastralgia that prevented them from taking fluids, three had a high fever over 39 ${ }^{\circ} \mathrm{C}$, and four drunk alcohol heavily. Patients 2 and 6 had been diagnosed with viral gastro-colitis at their referring facilities one day before admission (Table 1). All patients with unknown $\mathrm{HH}$ presented at least one of the above symptoms, which could cause mild hypovolemia. On admission, all 15 patients of unknown HH showed a collapse of the external jugular vein when in the supine position without deterioration in cardiac output or reduced systolic blood pressure. Ten patients $(67 \%)$ had a mild fever $\left(>37^{\circ} \mathrm{C}\right)$ and $11(73 \%)$ had mild tachycardia $(>80 / \mathrm{min})$. None experienced a reduction in peripheral capillary oxygen saturation or respiratory disturbance. Hepatic encephalopathy was confirmed in three patients.

\section{Laboratory tests on admission and temporal changes during hospitalization}

The serum level of LDH of unknown HH was elevated in parallel with those of AST and ALT on admission, which is consistent with the typical features of HH (Table 2). The fibrin degradation product (FDP) concentration of unknown $\mathrm{HH}$ was increased except for patient No 5 (Table 2). The serum ferritin concentration which generally was not reported to be increased in $\mathrm{HH}$ was markedly elevated in all 15 patients in unknown $\mathrm{HH}$ (Table 2).

According to the current procedure in our hospital, patients were treated by transcatheter arterial steroid injection therapy (TASIT), plasma exchange, anti-coagulation treatment using recombinant thrombomodulin and antithrombin-III. The serum levels of ferritin, LDH, ALT, and PT-INR were rapidly decreased during hospitalization (Fig. 1) and all 15 patients with unknown $\mathrm{HH}$ recovered without any complication.

\section{Discussion}

Hypoxic hepatitis is generally caused by hemodynamic failure due to cardiac, respiratory, or septic/toxic shock,

Table 1. - Preceding episodes and vital signs of the patients of unknown HH on admission

\begin{tabular}{|c|c|c|c|c|c|c|c|c|c|}
\hline \multirow{2}{*}{ No. } & \multirow{2}{*}{ Age } & \multirow{2}{*}{ Sex } & \multirow{2}{*}{ Preceding episode } & \multirow{2}{*}{ Daily drinking } & \multicolumn{5}{|c|}{ Vital signs on admission } \\
\hline & & & & & B.T. $\left({ }^{\circ} \mathrm{C}\right)$ & B.P. $(\mathrm{mmHg})$ & H.R. (/min) & $\mathrm{SpO} 2(\%$, room air $)$ & H.E. \\
\hline 1 & 60 & Male & Appetite loss/heavy drinking & Heavy & 37.0 & $177 / 92$ & 60 & 96 & 0 \\
\hline 2 & 37 & Female & Vomiting/appetite loss & Heavy & 37.1 & $121 / 89$ & 91 & 97 & 0 \\
\hline 3 & 38 & Male & Vomiting/fever & Regular & 36.8 & $104 / 53$ & 88 & 97 & 0 \\
\hline 4 & 55 & Male & Epigastralgia/high fever & Regular & 38.7 & $151 / 102$ & 102 & 96 & 0 \\
\hline 5 & 40 & Female & Diarrhea/appetite loss/heavy drinking & Heavy & 36.3 & $145 / 87$ & 95 & 98 & 0 \\
\hline 6 & 18 & Female & Diarrhea/high fever & None & 38.9 & $126 / 91$ & 73 & 98 & 0 \\
\hline 7 & 37 & Female & Fever/appetite loss/heavy drinking & Regular & 37.1 & $115 / 57$ & 105 & 98 & 0 \\
\hline 8 & 71 & Male & High fever (influenza)/ appetite loss & None & 36.5 & $138 / 63$ & 71 & 98 & 0 \\
\hline 9 & 39 & Male & Vomiting/fever & None & 37.3 & $151 / 109$ & 90 & 98 & 0 \\
\hline 10 & 81 & Male & Heavy drinking & Heavy & 36.9 & $124 / 82$ & 99 & 95 & 3 \\
\hline 11 & 69 & Male & Vomiting/fever & Regular & 37.6 & $134 / 89$ & 102 & 96 & 2 \\
\hline 12 & 40 & Male & Vomiting/fever & Regular & 37.2 & $119 / 68$ & 62 & 98 & 0 \\
\hline 13 & 48 & Male & Vomiting/fever & Heavy & 37.2 & $126 / 60$ & 86 & 98 & 0 \\
\hline 14 & 21 & Male & Epigastralgia/appetite loss & None & 38 & $152 / 93$ & 93 & 99 & 1 \\
\hline 15 & 49 & Male & Vomiting/fever & Regular & 37.6 & $117 / 68$ & 93 & 94 & 0 \\
\hline
\end{tabular}

Abbreviations : B.T., body temperature ; B.P., blood pressure ; H.R., heart rate ; SpO2, peripheral capillary oxygen saturation ; H.E., hepatic encephalopathy. 
Table 2. - Individual laboratory data on admission and treatments of patients with unknown HH

\begin{tabular}{|c|c|c|c|c|c|c|c|c|c|c|}
\hline \multirow[t]{2}{*}{ No } & AST & ALT & $\mathrm{LDH}$ & Ferritin & \multirow[t]{2}{*}{ PT-INR } & FDP & \multirow[t]{2}{*}{ TASIT } & \multirow[t]{2}{*}{$\mathrm{PE}$} & \multirow[t]{2}{*}{ rTM } & \multirow[t]{2}{*}{ AT-III } \\
\hline & (IU/L) & (IU/L) & (IU/L) & (ng/mL) & & $(\mu \mathrm{g} / \mathrm{mL})$ & & & & \\
\hline 1 & 5577 & 2615 & 5728 & 15580 & 1.81 & 17 & Done & Done & Done & Done \\
\hline 2 & 2619 & 2768 & 3036 & 3775 & 1.66 & 12.9 & ND & ND & ND & ND \\
\hline 3 & 7945 & 3543 & 3465 & 42369 & 2.43 & 9 & Done & Done & Done & Done \\
\hline 4 & 37968 & 9626 & 30499 & 146517 & 5.97 & 99.5 & Done & Done & Done & ND \\
\hline 5 & 4912 & 3241 & 3091 & 17467 & 1.74 & 5 & Done & Done & ND & ND \\
\hline 6 & 9483 & 6607 & 8477 & 11940 & 1.64 & 57.9 & Done & Done & Done & Done \\
\hline 7 & 15565 & 6113 & 10520 & 46530 & 4.17 & 18.4 & Done & Done & ND & Done \\
\hline 8 & 2241 & 2349 & 1523 & 6631 & 1.68 & 11.7 & ND & Done & Done & Done \\
\hline 9 & 3755 & 2682 & 2394 & 6651 & 1.59 & 5.1 & Done & Done & Done & Done \\
\hline 10 & 4588 & 1819 & 3068 & 54254 & 5.32 & 26.5 & Done & Done & Done & Done \\
\hline 11 & 5497 & 1974 & 4320 & 27850 & 2.07 & 24.2 & ND & ND & ND & Done \\
\hline 12 & 6200 & 3076 & 3874 & 115930 & 1.8 & 15 & Done & Done & Done & Done \\
\hline 13 & 20272 & 5679 & 8634 & 213600 & 2.37 & 31.6 & Done & Done & Done & Done \\
\hline 14 & 6921 & 4780 & 5035 & 14377 & 1.91 & 182.4 & Done & Done & Done & Done \\
\hline 15 & 18391 & 7274 & 8123 & 251970 & 2.5 & 15.3 & Done & Done & Done & Done \\
\hline
\end{tabular}

Abbreviations : AST, aspartate transaminase ; ALT, alanine transaminase ; $\gamma$-GTP, $\gamma$-glutamyl transpeptidase ; LDH, lactate dehydrogenase ; ALP, alkaline phosphatase ; BUN, blood urea nitrogen ; PT-INR, prothrombin time-international normalized ratio ; FDP, fibrin degradation product ; TASIT, transcatheter arterial steroid injection therapy ; PE, plasma exchange ; rTM, recombinant thrombomodulin ; AT-III, antithrombin-III ; ND, not done.
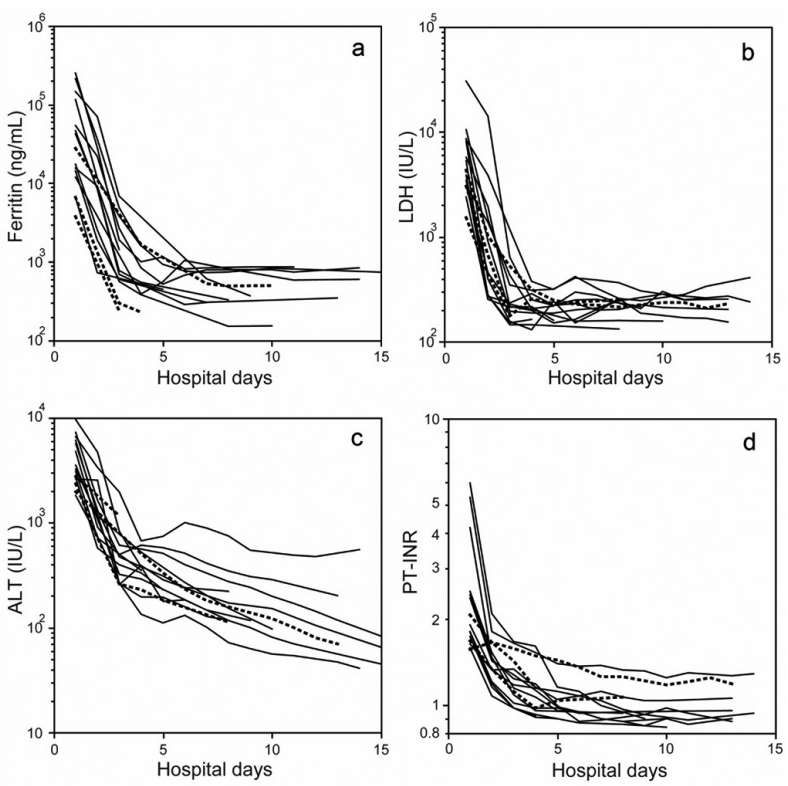

Figure 1. - Temporal changes of serum concentrations of ferritin (a), LDH (b), and ALT (c), and PT-INR (d) in unknown $\mathrm{HH}$ patients during the first 2 weeks of hospitalization.

but there are particular forms of hypoxic hepatitis (36). A variety of causes have been reported to cause $\mathrm{HH}$ such as hypoglycemia, liver cirrhosis, diffuse metastatic infiltration into the liver, heatstroke, sickle cell disease, grand mal seizure, extreme anemia, obstructive sleep apnea, aortic aneurysm, acute lower limb ischemia, Budd-Chiari syndrome, and hereditary hemorrhagic telangiectasia (2). However, underlying diseases or episodes could not be identified in some cases of $\mathrm{HH}$.

We report another form of hypoxic $\mathrm{HH}$ hitherto not reported: $\mathrm{HH}$ with marked elevation of serum ferritin (HH with hyperferritinemia). Our hypothesis is that endotoxemia due to intestinal barrier dysfunction might activate intrahepatic macrophages which results in sinusoidal fibrin deposition and consequent hepatic microcirculatory impairment. All 15 patients of $\mathrm{HH}$ with hyperferritinemia presented at least one digestive symptom such as vomiting, diarrhea, appetite loss, and epigastralgia and 11 patients were habitual drinkers (Table 1). It is well known that habitual drinkers are prone to portal endotoxemia because their intestinal barrier function is dysregulated (8) and endotoxin activates macrophage and stimulate the production of ferritin $(9,10)$. The median concentration of serum ferritin of 15 patients was $27850 \mathrm{ng} / \mathrm{mL}$, which is comparable to the level observed in patients with hemophagocytic lymphohistiocytosis in which activated macrophages are supposed to secrete large amount of ferritin (11). The fact that activation of intrahepatic macrophages can induce sinusoidal fibrin deposition and subsequent hepatic microcirculatory impairment has been demonstrated in murine acute liver injury models $(12,13)$ and human acute liver failure caused by HAV or HBV $(14,15)$. In addition, Shibayama et. al. reported fibrin thrombi were observed around the centrilobular necrotic area in hepatic congestion patients and they speculated its pathogenesis could be portal endotoxemia (16).

Another possible mechanism of hyperferritinemia in HH might be upregulated autophagy in hepatocytes under malnutrition. A slight elevation of serum ferritin and hepcidin was reported in anorexia nervosa (AN) patients even though their liver function tests were normal (17). Although the precise mechanism of hepcidin upregulation in AN remains unknown, increased hepcidin binds to its receptor ferroportin on duodenal enterocytes, hepatocytes, and macrophages and inhibits iron secretion from these cells, which results in elevated ferritin levels in these cells and serum (18). On the other hand, starvation promotes autophagy to provide amino acids as cellular energy source (19). Malnutrition in AN promotes hepatocellular autophagy which initially 
helps hepatocytes to cope with malnutrition but finally progress to autophagic cell death (19). Although marked elevation of serum liver enzymes including AST, ALT, and $\mathrm{LDH}$ is not common in $\mathrm{AN}$, there are several case reports in severe AN patients (20-22). Unfortunately, serum ferritin concentration was not described in these reports, however, it is plausible that increased ferritin content in hepatocytes might be deviated into blood concomitant with liver enzymes. Given that $\mathrm{HH}$ patients with hyperferritinemia tended to be undernourished because they had digestive symptoms and were habitual drinkers, hepatocyte autophagy might be involved in the pathogenesis of $\mathrm{HH}$ with hyperferritinemia.

Accordingly, we treat our patients by transcatheter arterial steroid injection therapy (TASIT), plasma exchange, anti-coagulation treatment using recombinant thrombomodulin and antithrombin-III. TASIT is a procedure we developed in 2005 to treat patients with acute liver failure, intending to reduce the activity of intrahepatic macrophages (14). Briefly, each patient was injected with $1,000 \mathrm{mg} /$ day methylprednisolone for three days via a catheter placed in the proper hepatic artery. Of the 15 patients of $\mathrm{HH}$ with hyperferritinemia, 12 underwent TASIT, 13 underwent PE, and 13 received anticoagulant treatment with recombinant thrombomodulin and/or antithrombin-III (Table 2). Although, the prognosis of $\mathrm{HH}$ patients is generally poor (3-6), all of 15 patients of $\mathrm{HH}$ with hyperferritinemia recovered without complication. Given that activated macrophages may play a pivotal role in HH with hyperferritinemia, a strong anti-inflammatory effect exerted by direct steroid administration into the livers by TASIT may contribute to the good prognosis of our patients.

\section{Conclusion}

We analyzed the acute liver injury patients without any underlying disease or episode which are known to result in $\mathrm{HH}$ and found they were characterized by marked elevation of serum ferritin concentration. The pathogenesis of this particular $\mathrm{HH}$ group might be intrahepatic macrophage activation due to portal endotoxemia or autophagic hepatocyte death under malnutrition. Anti-inflammatory treatments might be effective for this group of hypoxic hepatitis.

\section{Conflict of interest statement}

All authors have no conflict of interest.

\section{References}

1. HENRION J. Hypoxic hepatitis. Liver Int. 2012, 32(7) : 1039-1052.

2. WASEEM N., CHEN P.H. Hypoxic Hepatitis: A Review and Clinical Update. J. Cli. Transl. Hepatol. 2016, 4(3) : 263-268.

3. HENRION J., SCHAPIRA M., LUWAERT R., COLIN L., DELANNOY A., HELLER F.R. Hypoxic hepatitis : clinical and hemodynamic study in 142 consecutive cases. Medicine (Baltimore). 2003, 82(6) : 392-406.

4. BIRRER R., TAKUDA Y., TAKARA T. Hypoxic hepatopathy : pathophysiology and prognosis. Intern. Med. 2007, 46(14) : 1063-1070.

5. FUHRMANN V., KNEIDINGER N., HERKNER H., HEINZ G., NIKFARDJAM M., BOJIC A., et al. Hypoxic hepatitis: underlying conditions and risk factors for mortality in critically ill patients. Intensive Care Med. 2009, 35(8) : 1397-1405.

6. RAURICH J.M., LLOMPART-POU J.A., FERRERUELA M., COLOMAR A., MOLINA M., ROYO C., et al. Hypoxic hepatitis in critically ill patients : incidence, etiology and risk factors for mortality. J. Anesth. 2011, 25(1) : 5056.

7. LIANG R., LIU A., PERUMPAIL R.B., WONG R.J., AHMED A. Advances in alcoholic liver disease: An update on alcoholic hepatitis. World $J$. Gastroenterol. 2015, 21(42) : 11893-11903.

8. GONZ LEZ-REIMERS E., SANTOLARIA-FERN NDEZ F., MART N-GONZ LEZ M.C., FERN NDEZ-RODR GUEZ C.M., QUINTEROPLATT G. Alcoholism : a systemic proinflammatory condition. World $J$. Gastroenterol. 2014, 20(40) : 14660-14671.

9. STRIPPOLI R., CARVELlO F., SCIANARO R., DE PASQUALE L., VIVARELLI M., PETRINI S., et al. Amplification of the response to Toll-like receptor ligands by prolonged exposure to interleukin-6 in mice : implication for the pathogenesis of macrophage activation syndrome. Arthritis Rheum. 2012, 64(5) : 1680-1688.

10. GLASS C.K., NATOLI G. Molecular control of activation and priming in macrophages. Nat. Immunol. 2016, 17(1) : 26-33.

11. SCHWEIZER M., GOEDE J.S., BRINER V. Patients with an extraordinarily elevated serum ferritin: think of haemophagocytic lymphohistiocytosis. Swiss Med. Wkly. 2015, 145 : w14152.

12. KATO J., OKAMOTO T., MOTOYAMA H., UCHIYAMAR., KIRCHHOFER D., VAN ROOIJEN N., et al. Interferon-gamma-mediated tissue factor expression contributes to T-cell-mediated hepatitis through induction of hypercoagulation in mice. Hepatology. 2013, 57(1) : 362-372.

13. TANAKA M., TANAKA K., MASAKI Y., MIYAZAKI M., KATO M., $\mathrm{KOTOH} \mathrm{K.,} \mathrm{et} \mathrm{al.} \mathrm{Intrahepatic} \mathrm{microcirculatory} \mathrm{disorder,} \mathrm{parenchymal}$ hypoxia and NOX4 upregulation result in zonal differences in hepatocyte apoptosis following lipopolysaccharide- and D-galactosamine-induced acute liver failure in rats. Int. J. Mol. Med. 2014, 33(2) : 254-262.

14. KOTOH K., KATO M., KOHJIMA M., NAKAMUTA M., ENJOJI M. A new treatment strategy for acute liver failure. World J. Hepatol. 2010, 2(11) : 395400.

15. КОTOH K., KATO M., KOHJIMA M., TANAKA M., MIYAZAKI M., NAKAMURA K., et al. Lactate dehydrogenase production in hepatocytes is increased at an early stage of acute liver failure. Exp. Ther. Med. 2011, 2(2) : 195-199.

16. SHIBAYAMA Y., URANO T., ASAKA S., HASHIMOTO K., NAKATA K. Pathogenesis of centrilobular necrosis following congestion of the liver. $J$ Gastroenterol. Hepatol. 1993, 8(6) : 530-534.

17. PAPILLARD-MARECHAL S., SZNAJDER M., HURTADO-NEDELEC M., ALIBAY Y., MARTIN-SCHMITT C., DEHOUX M., et al. Iron metabolism in patients with anorexia nervosa : elevated serum hepcidin concentrations in the absence of inflammation. Am. J. Clin. Nutr. 2012, 95(3) : 548-554.

18. ANDERSON G.J., FRAZER D.M. Current understanding of iron homeostasis. Am. J. Clin. Nutr. 2017, 106(Suppl 6) : 1559s-1566s.

19. KHELOUFI M., BOULANGER C.M., DURAND F., RAUTOU P.E. Liver autophagy in an nervosa and acute liver injury. Biomed. Res. Int. 2014, 2014 : 701064.

20. DI PASCOLI L., LION A., MILAZZO D., CAREGARO L. Acute liver damage in anorexia nervosa. Int. J. Eat Disord. 2004, 36(1) : 114-117.

21. DE CAPRIO C., ALFANO A., SENATORE I., ZARRELLA L., PASANISI F., CONTALDO F. Severe acute liver damage in anorexia nervosa : two case reports. Nutrition. 2006, 22(5) : 572-575.

22. RAMSOEKH D., TAIMR P., VANWOLLEGHEM T. Reversible severe hepatitis in anorexia nervosa: a case report and overview. Eur. J. Gastroenterol. Hepatol. 2014, 26(4) : 473-477. 